Article

\title{
Design and Freight Corridor-Fleet Size Choice in Collaborative Intermodal Transportation Network Considering Economies of Scale
}

\author{
Dan Liu ${ }^{1,2, * \mathbb{C}}$, Zhenghong Deng ${ }^{3, *}$, Qipeng Sun ${ }^{4}$, Yong Wang ${ }^{5}$ and Yinhai Wang ${ }^{6}$ \\ School of Economics and Management, Chang'an University, Xi'an 710064, Shaanxi, China \\ 2 Freight Mobility Research Institute, Department of Civil, Environmental and Geomatics Engineering, \\ Florida Atlantic University, Boca Raton, FL 33431, USA \\ 3 School of Automation, Northwestern Polytechnical University, Xi'an 710064, Shaanxi, China \\ 4 School of Economics and Management; Economics and management research center for integrated \\ transportation, Chang'an University, Xi'an 710064, Shaanxi, China; sunqip2003@163.com \\ 5 School of Economics and Management, Chongqing Jiaotong University, Chongqing 400074, China; \\ yongwx6@gmail.com \\ 6 Department of Civil and Environmental Engineering, University of Washington, Seattle, WA 98195, USA; \\ yinhai@uw.edu \\ * Correspondence: danbi129@163.com or liud@fau.edu (D.L.); dthree@nwpu.edu.cn (Z.D.)
}

Received: 23 January 2019; Accepted: 11 February 2019; Published: 14 February 2019

\begin{abstract}
Decentralized freight decision has been proved to be one of the inhibitors to achieve a sustainable transport network. One important method also a key challenge is to determine how to coordinate and consolidate the transportation flow to get the best logistics performance. This study presents an intermodal transportation network considering freight consolidation through freight forwarders' cooperation. We formulate the problem as a minimum intermodal transport cost model, which is a nonlinear, nonconvex and discontinuous function that involves volume economies of scale, distance economies of scale and vehicle size economies of scale. A hybrid genetic algorithm (GA) and particle swarm optimization (PSO) algorithm in combination with a batch strategy are used to solve the problem. Five different transport demand scenarios are tested on a real case on "China Railway Express" (Crexpress). The choices of reasonably corridor and fleet size combination are provided.
\end{abstract}

Keywords: collaborative intermodal transportation network; tactical planning; batch strategy; genetic algorithm and particle swarm optimization algorithm; economies of scale

\section{Introduction}

Well-functioning transport networks and corridors are essential for sustainable transport network design. One fundamental imperative for the sustainable transport network design is maximizing the utilization of the transport and terminal capacity with minimal cost, while supporting the freight flows of multiple shippers. A centralized decision maker, such as a freight forwarder must balance the need to provide customized solutions to its shipper with the economic benefits of maximizing consolidation regarding freight and terminal capacity, using a single network. Usually, freight forwarders focus on a specific type of cargo, a valuable service provided by freight forwarder is to manage freight transportation from multiple shippers to several destinations. A crucial challenge that the freight forwarder faces is to determine how to coordinate and consolidate the transportation flows, to minimize the total transport cost. One tactic is to cooperation between origin terminals that collect shipments from multiple shippers and then send the consolidated shipments to each destination terminal or destination. 
Collaborative transportation planning can be used as a powerful instrument to improve the operational performance of freight forwarders with limited business size, also reduce the suppliers' logistics cost (Hoeffler et al. [1], McGinnis et al. [2]) because they can take advantage of both economies of scope and economies of scale. Óscar Álvarez-SanJaime et al. [3] investigated two freight routes between the hinterlands of Genoa and Antwerp and the hinterlands of Valencia. Their results show that integration between two shipping lines shows strong economies of scale, which leads to a decrease in total transport cost. The commonly estimated possible cost reduction through cooperation amounts to $5-15 \%$ (Cruijssen and Salomon [4]; Krajewska et al. [5]). Verdonck et al. [6] provide an extensive review of the collaborative distribution literature. Most studies consider carriers collaboration in transportation planning. Under a collaborative mechanism, carriers exchange shipment demands to increase vehicle capacity utilization and profitability (Agarwal and Ergun [7]; Chen [8]; Dai et al. [9]; Hernández et al. [10]; Liu et al. [11]; Wang and Kopfer [12] ). However, a single carrier usually operates one kind of transportation mode, so their cooperation without information about the market and public carriage usually cannot minimize the total logistics cost of the whole network. These cooperation mechanisms do not apply to the freight forwarders' cooperation, because the corridor choice and vehicle arrangement strategies are seldom considered in the collaborative transportation network, which can be used to improve the performance of the generated consolidation scheme further.

Motivated by practical oil and gas $(O \& G)$ equipment industry, many $O \& G$ equipment suppliers rely on local carriers or forwards who supplies transportation service for them. Meanwhile, a local freight forwarder who is asked to deliver outside his facility is facing the increasing cost issues due to empty, idle capacity, backhauls and rising fuel prices. It is estimated that the freight costs are inflated $15 \%-30 \%$ due to the decentralized freight decisions of forwarders (A PLS Logistics White Paper, 2013). Therefore, the transportation planning of $O \& G$ equipment is a non-trivial issue in the $O \& G$ industry.

This study investigates a collaborative intermodal transportation network considering the corridor choice and vehicle arrangements simultaneously. A unit cost function is first developed to capture the characteristics of the economics of scale in the collaborative intermodal freight transport network, relevant researches refer to Christiansen et al. [13]; Bektas and Crainic [14]; Caris et al. [15]; M. SteadieSeif [16] and Anny-del-Mar [17]. Considering the economics of scale, Kimms [18] and Racunica and Wynter [18] present an optimization model that addresses the problem of economies of scale brought about by freight consolidation through using a hub-and-spoke network. 1llia Racunica [19] used a linearization procedure along two efficient variable-reduction heuristics to solve the problem, which worked well on the small-scale problem. Except for quantity economies of scale, Janic [20] developed a model calculating the full costs of a given intermodal network considering economies of scale and external costs. The small-scale network was tested with exact solutions. Nam Seok Kim [21] proposes a multimodal minimum cost flow problem considering quantity economies of scale (QES), distance economies of scale (DES) and vehicle size economies of scale (VES), a GA-based heuristic algorithm is applied to find an acceptable mode, route and vehicle arrangement strategy. A summary of the relevant works of literature is shown in Table 1.

In this paper, the corridor-fleet choice problem in a collaborative intermodal transportation network is formulated as a minimum transport cost (MTC) model with the optimization objective of minimizing the total transport cost of the whole system. The generated consolidation scheme specifies and the multiple transportation services are considered. As the formulated model is nonlinear, nonconvex and discontinuous, it is hard to obtain an optimal solution within a reasonable computational time. An efficient GA-PSO algorithm with a batch strategy is applied to resolve the model to get a near-optimal solution efficiently. 
Table 1. Summary of literature reviews.

\begin{tabular}{|c|c|c|c|c|c|c|}
\hline Reference & Mode & Transport Links & $\begin{array}{l}\text { Collaboration } \\
\text { Parters }\end{array}$ & $\begin{array}{l}\text { Economies } \\
\text { of Scale }\end{array}$ & Model & Solution \\
\hline $\begin{array}{l}\text { Cruijssen and } \\
\text { Salomon (2004) }\end{array}$ & truck & / & $\begin{array}{l}\text { transport } \\
\text { companies }\end{array}$ & / & vehicle routing & $\begin{array}{c}\text { scenario } \\
\text { comparison }\end{array}$ \\
\hline I. Racunica (2005) & truck & hub-destination & / & QES & $\begin{array}{l}\text { a mixed-integer } \\
\text { programming }\end{array}$ & heuristics \\
\hline Janic (2007) & truck, rail & $\begin{array}{l}\text { pre-/post-haulage, } \\
\text { long-distance link }\end{array}$ & / & DES & vehicle routing & $\begin{array}{c}\text { scenario } \\
\text { comparision }\end{array}$ \\
\hline $\begin{array}{c}\text { Krajewska et al. } \\
(2008)\end{array}$ & truck & / & carrier & / & vehicle routing & local search \\
\hline Ekki D (2008) & truck, rail & / & / & DES & bundling model & $\begin{array}{l}\text { generic } \\
\text { approach }\end{array}$ \\
\hline Liu et al. (2010) & truck & / & $\begin{array}{l}\text { full-truckload } \\
\text { carrier }\end{array}$ & & vehicle routing & $\begin{array}{l}\text { two-phase } \\
\text { heuristic }\end{array}$ \\
\hline $\begin{array}{l}\text { Álvarez-SanJaime } \\
\text { et al. (2013) }\end{array}$ & truck, vessel & / & $\begin{array}{l}\text { freight } \\
\text { forwarder }\end{array}$ & QES & $\begin{array}{c}\text { market } \\
\text { equilibrium }\end{array}$ & $\begin{array}{l}\text { empirical } \\
\text { application }\end{array}$ \\
\hline Dai et al. (2014) & truck & / & carrier & / & vehicle routing & $\begin{array}{l}\text { pricing-setting, } \\
\text { lagrangian } \\
\text { relaxation }\end{array}$ \\
\hline $\begin{array}{l}\text { Xin Wang et al. } \\
\text { (2014) }\end{array}$ & truck & / & $\begin{array}{l}\text { less-than-truckload } \\
\text { carrier }\end{array}$ & / & vehicle routing & $\begin{array}{c}\text { neighborhood } \\
\text { search heuristic }\end{array}$ \\
\hline T. Yamada (2015) & truck & $\begin{array}{l}\text { supply chain, } \\
\text { intermodal }\end{array}$ & / & / & $\begin{array}{c}\text { bi-level } \\
\text { programming }\end{array}$ & $\begin{array}{l}\text { particle swarm } \\
\text { optimization }\end{array}$ \\
\hline $\begin{array}{c}\text { Nam Seok Kim } \\
(2016)\end{array}$ & $\begin{array}{l}\text { truck, rail, } \\
\text { vessel }\end{array}$ & $\begin{array}{c}\text { pre-/post- } \\
\text { haulage, } \\
\text { long-distance link }\end{array}$ & / & $\begin{array}{l}\text { QES, DES } \\
\text { VES }\end{array}$ & $\begin{array}{c}\text { vehicle } \\
\text { routing-fleet size }\end{array}$ & $\begin{array}{l}\text { genetic } \\
\text { algorithm }\end{array}$ \\
\hline H. Chen (2016) & truck & / & carrier & / & vehicle routing & $\begin{array}{c}\text { column } \\
\text { generation-based } \\
\text { heuristic }\end{array}$ \\
\hline
\end{tabular}

The contributions of this study to the field are as follows.

Firstly, a collaborative intermodal transportation network representation considering freight consolidation between origin terminals is described, where a freight forwarder serves as a central decision maker coordinating transportation activities. As far as we know, this is the first time that freight corridor-fleet size choice is being considered at the same time in a collaborative intermodal transportation network, which may shed light on the tactical freight network design.

Secondly, we build the MTC model based on the cost structures used in practice for each transport mode and transshipment. And the model is formulated as generalized costs for moving one unit of each type of commodity. The unit cost is the function of volume, distance and vehicle size, which reflects three different kinds of economies of scale at the same time, QES, DES and VES.

Thirdly, due to the non-linear, discontinuous and non-convex of the model, a batch strategy combined with hybrid genetic algorithm (GA) and particle swarm optimization (PSO) is developed to efficiently solve the MTC model.

Also, we design a scenario analysis using aggregate data from the transport agency and disaggregate data from the oil and gas drilling equipment companies, the findings and conclusions may provide the references for the transportation agencies and transportation enterprises.

The remainder of this paper is organized as follows. We present the problem and network representation in Section 2. The model and solution approaches which are used to solve the MTC model are presented in Sections 3 and 4 respectively. Section 5 shows the computational results in scenario studies. Section 6 concludes this paper.

\section{Problem Description and Network Representation}

The suppliers of $O \& G$ drilling equipment usually distribute in different regions and produce one or serval kinds of equipment components due to the high personalization and specificity of the O\&G equipment. Drilling sites usually located in regions with rich oil or gas resources. Drill sites usually 
need various equipment components to be assembled. In Figure 1, the components of the network include equipment suppliers, drill sites, transshipment, terminals and links in different transport stages (pre/post-haulage, transshipment link, long-distance link).

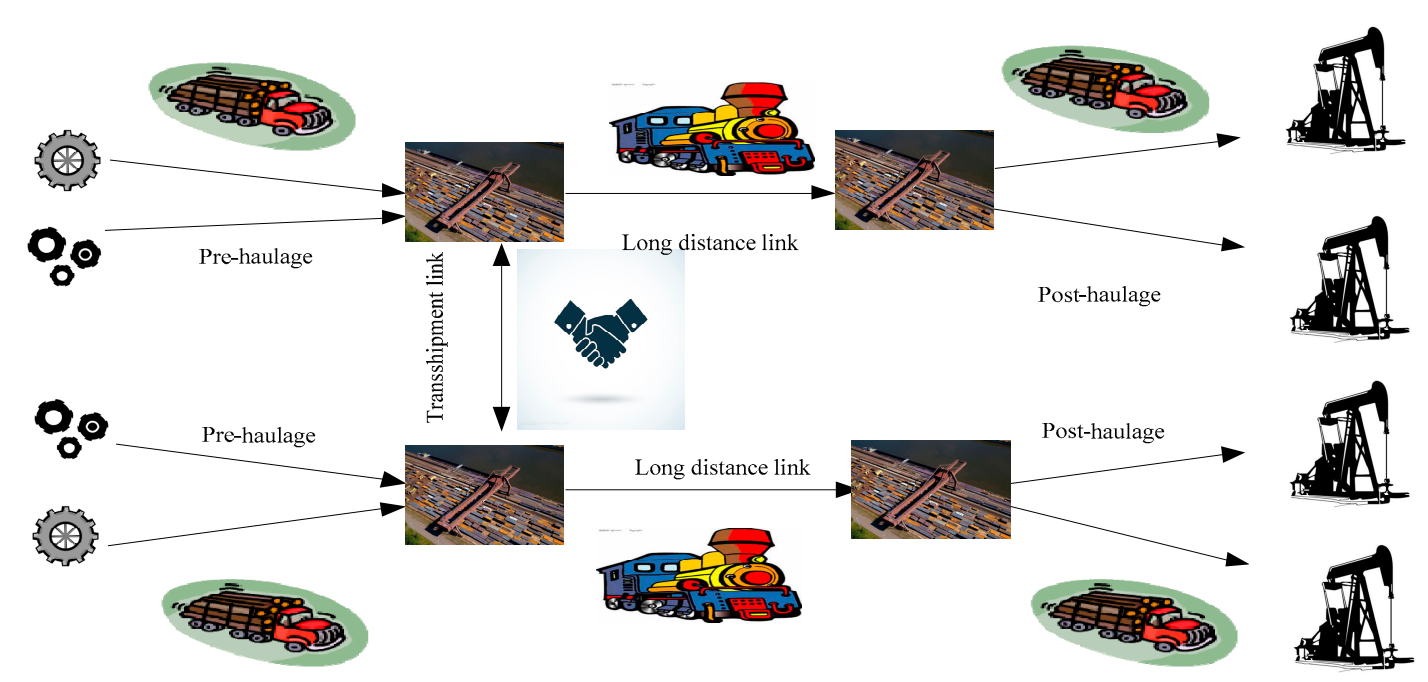

Figure 1. Collaborative intermodal transportation network for $O \& G$ drilling equipment.

In this collaborative intermodal freight transport network, there are three kinds of links, which are the long-distance link, pre-/post-haulage and transshipment link. The distinction between different kinds of the link is based on the cost structures in practice for each link. Long-distance link connects between terminals which services suppliers and drill sites, the cost of long-distance link mainly relates to the distance between the origin and the destination, including depreciation, interest, insurance, facility tax, repairs and fuel, et al. The transportation modes can be rail, air, sea, inland waterway or various combinations. Here we only consider road and rail transportation. Also, the term 'pre/post-haulage' is used to describe the haulage between suppliers and origin terminals, or the haulage between destination terminals and drilling sites. The pre/post-haulage costs describe the transport costs between a location and a terminal within a region. There are region-related costs which depend on the average traffic density, the wage of the region and the density of the transport demand generated close to the terminal. Road and rail modes can be chosen along the pre-/post-haulage in our study. Besides, the transshipment link connects a pair of two original terminals. The cost structure of the transshipment is different from transport costs. The costs of terminal operators are the handling costs which depend on the terminal throughput and the scale of the terminal. For a terminal operating under its capacity, an increase in throughput results in reduced unit handling costs, known as the 'economies of scale.' Conversely, the inefficiency in handling would increase the unit handling costs, if throughput continuously increases and causes congestion in the terminal.

Based on the transportation links with different modes, there are three classes of alternative transport services in this network, unimodal transportation service from a supplier to a drill site; intermodal rail transport without consolidation (pre-haulage $\rightarrow$ long-distance link $\rightarrow$ post-haulage); and intermodal rail transport with consolidation (pre-haulage $\rightarrow$ transshipment $(\mathrm{s}) \rightarrow$ long-distance link $\rightarrow$ transshipment (s) $\rightarrow$ post-haulage).

A transportation service (i.e., combination) consist of links is a path from a supplier to a drill site. Each link can be seen as one transport stage. Its transportation capacity depends on the selected transportation mode, that is, road, rail.

The following Example 1 shows nine transportation services of the road-rail intermodal transportation network.

Example 1. Let's consider a case with one supplier and one drill site. Here we only consider two kinds of transportation modes, rail and road, denoted as $u$. There are nine alternative transport services illustrated in 
Figure 2, including unimodal road transport service $\left(m_{u}=1\right)$, traditional intermodal transportation services $\left(m_{u}=2,3,4\right.$ and 5$)$ and collaborative transportation services $\left(m_{u}=6,7,8\right.$ and 9$)$, where consolidation are made in some original terminals. Services $m_{u}=1,2,3,4$ and 5 have three stages (links) ( $m_{u}=1$ have three stages with virtual terminals) and services $m_{u}=6,7,8$ and 9 have four stages (links). Here, we only consider rail transportation as the transshipment link and the long-distance link.

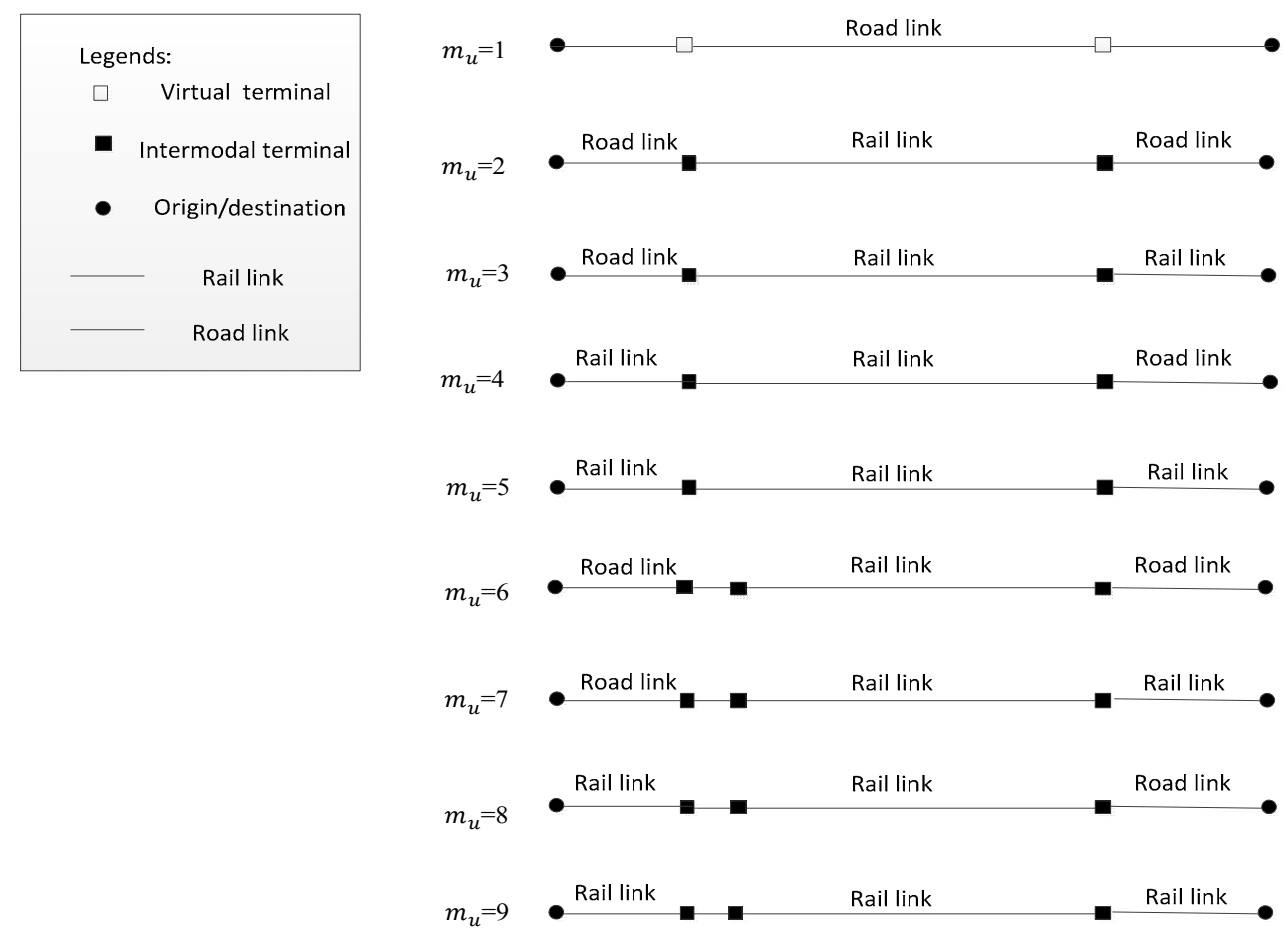

Figure 2. Transportation services in a collaborative intermodal transportation network.

Table 2 further describes the transport service according to Figure 2, where number 1 and 0 indicate exist and not exist; $m_{u}=1$, represents unimodal transportation; $m_{u}=2$, long-distance link is non-road link; $m_{\mathcal{u}}=3$, long-distance link and post-haulage are non-road links, post-haulage penalty = $1 ; m_{u}=4$, pre-haulage and long-distance link are non-road links, pre-haulage penalty $=1 ; m_{u}=5$, all the links are non-road links, pre/post-haulage penalty $=1 ; m_{u}=6,7,8,9$, transshipment link exists between two initial terminals based on transport service choice $2-5$.

Table 2. Description of feasible intermodal choice sets.

\begin{tabular}{|c|c|c|c|c|c|c|c|}
\hline $\begin{array}{l}\text { Service } \\
\qquad\left(m_{u}\right)\end{array}$ & $\begin{array}{c}\text { Pre-Haulage } \\
\text { Penalty }\end{array}$ & $\begin{array}{c}\text { Pre-Haulage } \\
k_{1}\end{array}$ & $\begin{array}{l}\text { Transshipment } \\
\text { Link } k_{2} \\
\end{array}$ & $\begin{array}{c}\text { Transshipment } \\
\text { Penalty }\end{array}$ & $\begin{array}{l}\text { Long-Distance } \\
\text { Link } k_{3}\end{array}$ & $\begin{array}{c}\text { Post-Haulage } \\
k_{4}\end{array}$ & $\begin{array}{c}\text { Post-Haulage } \\
\text { Penalty }\end{array}$ \\
\hline 1 & 0 & road & 0 & 0 & road & road & 0 \\
\hline 2 & 0 & road & 0 & 0 & rail & road & 0 \\
\hline 3 & 0 & road & 0 & 0 & rail & rail & 1 \\
\hline 4 & 1 & rail & 0 & 0 & rail & road & 0 \\
\hline 5 & 1 & rail & 0 & 0 & rail & rail & 1 \\
\hline 6 & 0 & road & rail & 1 & rail & road & 0 \\
\hline 7 & 0 & road & rail & 1 & rail & rail & 1 \\
\hline 8 & 1 & rail & rail & 1 & rail & road & 0 \\
\hline 9 & 1 & rail & rail & 1 & rail & rail & 1 \\
\hline
\end{tabular}

\section{Problem Statement and Formulation}

\subsection{Notation Definition}

To formulate MTC model, the collaborative intermodal freight network is firstly reduced to a network graph $W=(N, L)$, where $N$ is the set of nodes and $L$ is the set of arcs. Here, there are four 
subsets of nodes: production nodes $(O)$, destination nodes $(D)$, origin terminals $\left(T_{O}\right)$ and destination terminals $\left(T_{D}\right)$. We have $N=O \cup D \cup T_{O} \cup T_{D}$. Accordingly, four kinds of links can be distinguished: pre-haulage $\left(o, t_{o}\right), o \in O, t_{o} \in T_{O}$, post-haulage $\left(t_{d}, d\right), t_{d} \in T_{D}, d \in D$, transshipment link $\left(t_{o}, t_{o}\right)$, $t_{o}, t_{o^{\prime}} \in T_{O}$ and long-distance link $\left(t_{o}, t_{d}\right), t_{o} \in T_{O} t_{d} \in T_{D}$. Based on the network, the set of alternative transportation service from a supplier to a drilling site is identified as $M$ and here we only consider two kinds of transportation modes, rail and road, denoted as $u$, accordingly an alternative service is denoted as $m_{u}, m_{u} \in M$. And a link is indexed as $k_{n} \in K$. We use binary variable $e_{o t_{o}}^{k_{1}}=1$ denote a link $\left(o, t_{o}\right)$ exist in $k_{1}$ and $e_{o t_{o}}^{k_{1}}=0$ in the other case. Similarly, we use binary parameters $e_{t_{o} t_{o^{\prime}}}^{k_{2}}$, $e_{t_{0} t_{d}}^{k_{3}}$ and $e_{t_{d} d}^{k_{4}}$ to denote whether links $\left(t_{0}, t_{0^{\prime}}\right),\left(t_{0}, t_{d}\right)$ and $\left(t_{d}, d\right)$ exist in different transportation stage $k_{2}, k_{3}, k_{4}$. Variables $e_{t_{0}}, e_{t_{d}}$ denote if terminal $o$ or $d$ is open. The other main notations in this study are listed below.

\begin{tabular}{|c|c|}
\hline & Notation \\
\hline \multicolumn{2}{|l|}{ Parameters } \\
\hline$D_{i j}$ & given demand (TEU) between supplier $I$ and drill site $j, I \in O, j \in D$ \\
\hline$u$ & transportation mode (rail or truck) \\
\hline$m_{u}$ & transportation service, $m_{u} \in M$ \\
\hline$k_{n}$ & transportation stage, $k_{n} \in K$ \\
\hline$V^{u}$ & the availability of transportation mode $u$ (TEU/week) \\
\hline$P^{u}$ & handling ability of terminal (TEU/week) \\
\hline$v$ & vehicle type \\
\hline$\lambda^{v}$ & the load factor of each vehicle \\
\hline$S^{u v}$ & the capacity of each vehicle \\
\hline$c_{o t_{o}}^{k_{1}}$ & unit transport cost of pre-haulage $\left(o, t_{o}\right), o \in O, t_{o} \in T_{O}$ \\
\hline$c_{t_{0} t_{t^{\prime}}}^{k_{t_{0}}}$ & unit transport cost of transshipment link $\left(t_{o}, t_{0^{\prime}}\right), t_{o}, t_{0^{\prime}} \in T_{O}$ \\
\hline$c_{t_{o} t_{d}}^{k_{k} o^{\prime}}$ & unit transport cost of long-distance link $\left(t_{o}, t_{d}\right), t_{o} \in T_{O}, t_{d} \in T_{D}$ \\
\hline$c_{t_{d} d}^{k_{4} d a}$ & unit transport cost of post-haulage $\left(t_{d}, d\right), t_{d} \in T_{D}, \mathrm{~d} \in D$ \\
\hline$d_{o t_{o}}^{k_{1}}$ & distance of pre-haulage link $\left(o, t_{o}\right), o \in O, t_{o} \in T_{O}$ \\
\hline$d_{t_{0} t_{o^{\prime}}}^{k_{2}}$ & distance of transshipment link $\left(t_{o}, t_{0^{\prime}}\right), t_{o,} t_{o^{\prime}} \in T_{O}$ \\
\hline$d_{t_{o} t_{d}}^{k_{0} t_{o^{\prime}}}$ & distance of long-distance link $\left(t_{o}, t_{d}\right), t_{o} \in T_{O}, t_{d} \in T_{D}$ \\
\hline$d_{t_{d} d}^{k_{4} d}$ & distance of post-haulage link $\left(t_{d}, d\right), t_{d} \in T_{D}, \mathrm{~d} \in D$ \\
\hline $\operatorname{TSC}_{m}\left(k_{1}, k_{2}\right)$ & unit transshipment cost between $\left(k_{1}, k_{2}\right)$ \\
\hline $\operatorname{TSC}_{m}\left(k_{2}, k_{3}\right)$ & unit transshipment cost between $\left(k_{2}, k_{3}\right)$ \\
\hline$\delta_{\text {pre }}$ & penalty if pre-haulage is rail link \\
\hline$\delta_{\text {end }}$ & penalty if post-haulage is rail link \\
\hline$\delta_{t_{o}}$ & penalty if there is freight consolidation link between origin terminals \\
\hline \multicolumn{2}{|r|}{ 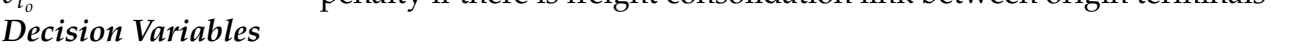 } \\
\hline$x_{i j}^{m_{u}}$ & number of container between $(i, j)$ using transport service, $i \in O, j \in D$ \\
\hline$e_{o t_{0}}^{k_{1}}$ & binary variable to denote a link $\left(o, t_{o}\right)$ exists in $k_{1}, o \in O, t_{o} \in T_{O}$ \\
\hline$e_{t_{0} t_{o^{\prime}}}^{k_{2}}$ & binary variable to denote a link $\left(t_{o}, t_{0^{\prime}}\right)$ exists in $k_{2}, t_{o}, t_{o^{\prime}} \in T_{O}$ \\
\hline$e_{t_{0} t_{d}}^{k_{3}}$ & binary variable to denote a link $\left(t_{o}, t_{d}\right)$ exists in $k_{3}, t_{o} \in T_{O}, t_{d} \in T_{D}$ \\
\hline$e_{t_{d} d}^{k_{4}}$ & binary variable to denote a link $\left(t_{d}, d\right)$ exists in $k_{4}, t_{d} \in T_{D}, d \in D$ \\
\hline$e_{t_{o}}$ & binary variable to denote if terminal $t_{o}$ is open \\
\hline$e_{t_{d}}$ & binary variable to denote if terminal $t_{d}$ is open \\
\hline
\end{tabular}

\subsection{Unit Cost Function}

The main motivation of looking for collaboration between freight forwarder in transport networks is achieving economies of scale and scope (Zinn and Parasuraman [22]; Gulati et al. [23]), which leads to reductions in average costs attributable to volume increases. The penalty cost for switching from one mode to anther through a path is considered. The following benefits are expected:

Distance economy of scale: The break-even distance of an intermodal freight network is crucial for freight forwarders or shippers to choose a specific freight transport mode (Ekki D. Kreutzberger [24]). 
The total cost of unimodal transport and intermodal transport are compared when transport distance is considered as a variable (JW [25]; Kim and Van Wee [26]; Resor et al. [27]). In Figure 3, there are five points $\left(O, H_{O}, H_{D}, B\right.$ and $\left.D\right)$. Point $O$ indicates the origin node at which the initial cost occurs. We assume that the initial costs for both the unimodal truck and intermodal system at point $O$ are equal. Point $\mathrm{H}_{\mathrm{O}}$ and $\mathrm{H}_{\mathrm{D}}$ are two intermodal terminals. $D$ is the final destination node. $B$ is the breakeven distance between unimodal truck transport and intermodal transport. $C_{H_{0}}$ and $C_{H_{D}}$ are the terminal cost occur at point $H_{O}, H_{D}$, which vary with the transport modes and the location.

Quantity economy of scale: Quantity economies of scope are reductions in average costs attributable to an increase in the number of goods transport or handling. Freight forwarders will have large volumes of freight to transfer through cooperation, through which there will be a volume discount and quantity economies of scale can be achieved, $Q_{e}$ is the breakeven quantity of different transport mode (see Figure 3).

Vehicle size economy of scale: The revolution in vehicles brought about by containerization has allowed carriers and terminals to take advantage of higher productivity in cargo transport and handling. As many different vehicle types and specifications can be described, the unit cost will change with the vehicle specification.

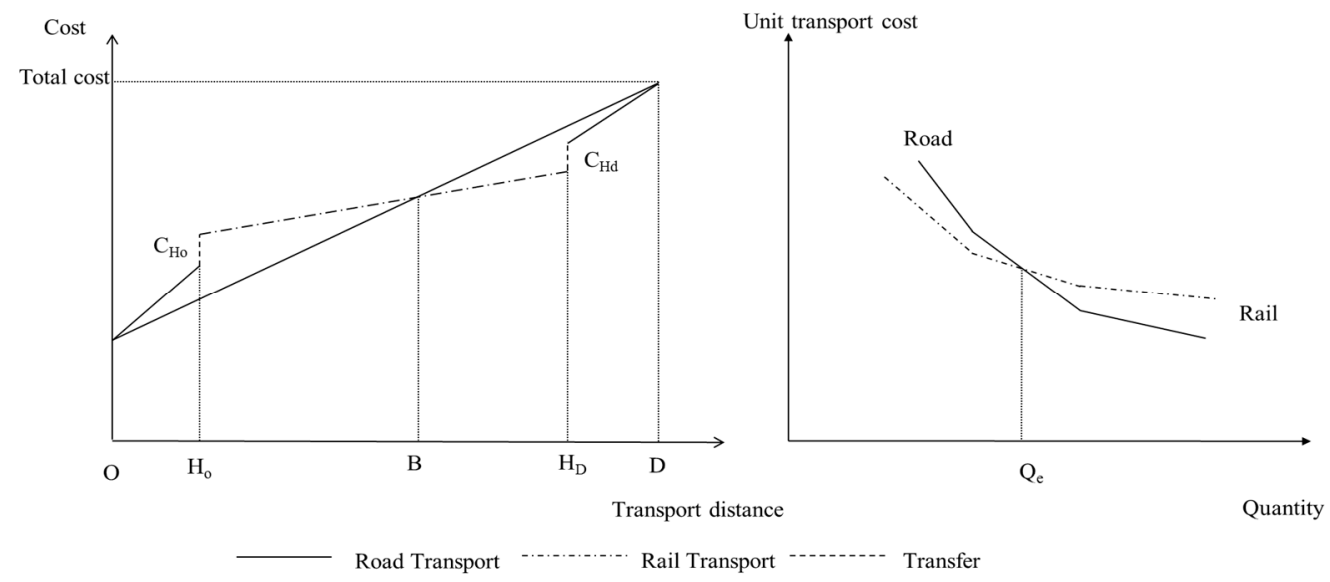

Figure 3. Cost for unimodal transport and intermodal transport. (based on Nam Seok Kim [26] and Lori Tavasszy [28]).

$\Omega_{i j}^{m_{u}}$ is the function of $m_{u}$. Based on the existing function of economies of scales, unit cost function in this problem is formulated as,

$$
\begin{gathered}
\Omega_{i j}^{m_{u}}=\delta_{\text {pre }}+C_{o t_{o}}^{k_{1}} d_{o t_{o}}^{k_{1}} e_{o t_{o}}^{k_{1}}+\operatorname{TSC}\left(k_{1}, k_{2}\right) e_{o t_{o}}^{k_{1}} e_{t_{o}}+C_{t_{o} t_{o^{\prime}}}^{k_{2}} d_{t_{o} t_{o^{\prime}}}^{k_{2}} e_{t_{o} t_{o^{\prime}}}^{k_{2}}+\delta_{t_{o}}+\operatorname{TSC}\left(\sum_{(i, j) \in L} x_{i j}^{k_{3}}\right) \\
e_{t_{o}}+C_{t_{o} t_{d}}^{k_{3}}\left(\sum_{(i, j) \in L} x_{i j}^{k_{3}}, d_{t_{o} t_{d^{\prime}}}^{k_{3}} S^{u v}\right) d_{t_{o} t_{d}}^{k_{3}} e_{t_{o} t_{d}}^{k_{3}}+\operatorname{TSC}\left(k_{3}, k_{4}\right) e_{t_{o} t_{d}}^{k_{3}} e_{t_{d}}+C_{t_{d} d}^{k_{4}} d_{t_{d} d}^{k_{4}} e^{k_{4}} t_{d} d+\delta_{\text {end }}
\end{gathered}
$$

where $\Omega_{i j}^{m_{u}}$ is the unit cost (\$/TEU) of the transportation service $m_{u}$ from supplier $i$ to a drilling site $j$. The unit $\operatorname{cost} C_{o t_{0}}^{k_{1}}, C_{t_{0} t_{o^{\prime}}{ }^{\prime}}^{k_{2}}, C_{t_{0} t_{d^{\prime}}}^{k_{3}}, C_{t_{d} d}^{k_{4}}$ (\$/TEU) are independent of three important factors contributing unit cost reductions: quantity, distance and vehicle size (discussed in Racunica and Wynter [19] and Jara-Diaz et al. [29]), which makes formula (2) a non-linear, discontinuous and non-convex function. Therefore, the unit cost function incorporating the dependencies associated with QES, DES and VES. Specifically, some freight modes might be quantity-sensitive while others might be distance sensitive (e.g., trucks) or vehicle-size sensitive (e.g., rail transport). Since an intermodal freight system consists of more than two modes, the cost function might different varied with the distance and include 
the effect of ESD. Usually, ESD may not play a significant role, because the distance is fixed in a given network. However, it is still worthwhile to include ESD because such cost function enables to consider the subtle trade-off between ESD gained long-distance trucking and diseconomies of scale for short distance of nonroad modes such as rail [26]. Transshipment costs between different links are distinguished. It is a function of modes involved. Finally, the demand in the unit cost function for transshipment and long-distance link indicated as $\sum_{(i, j) \in L} x_{i j}^{k_{3}}$ in $\operatorname{TSC}\left(\sum_{(i, j) \in L} x_{i j}^{k_{3}}\right)$ and $C_{t_{0} t_{d}}^{k_{3}}\left(\sum_{(i, j) \in L} x_{i j}^{k_{3}}, d_{t_{0} t_{d^{\prime}}}^{k_{3}} S^{u v}\right) d_{t_{0} t_{d}}^{k_{3}} e_{t_{0} t_{d^{\prime}}}^{k_{3}}$, is not for a single $O D$ pair but the summation of all $x_{i j}^{k_{3}}$.

\subsection{MTC Model}

The optimization objective of MTC model is to minimize the total network cost, formulated as:

Problem (P):

$$
C=\operatorname{Min} \sum_{(i, j) \in L} \sum_{m_{u} \in M_{i j}} \Omega_{i j}^{m_{u}} x_{i j}^{m_{u}}
$$

The constraints of MTC model are then formulated as follows.

$$
\begin{aligned}
& \sum_{m_{u} \in \mathrm{M}} x_{i j}^{m_{u}}=D_{i j}, \quad i \in O, j \in D \\
& \sum_{t_{o}} e_{o t_{o}}^{k_{1}}=1 \forall o \\
& e_{o t_{0}}^{k_{1}} \leq e_{t_{o}} \forall 0, t_{o} \\
& e_{t_{d} d}^{k_{4}} \leq e_{t_{d}} \forall d, t_{d} \\
& \sum_{t_{o}} e_{t_{o}} \leq 1 \forall t_{o} \\
& e_{t_{o} t_{0^{\prime}}}^{k_{2}} \leq e_{t_{0}} \forall t_{o}, t_{0^{\prime}} \\
& \sum_{o \in O} \sum_{t_{o} \in T_{o}} x_{o t_{o}}^{k_{1}} e_{o t_{o}}^{k_{1}} \geq \sum_{i \in O} \sum_{j \in D} x_{o d}^{k_{3}} e_{t_{o} t_{d}}^{k_{3}} \\
& \sum_{o \in O} \sum_{t_{o} \in T_{o}} x_{o t_{o}}^{k_{1}} e_{o t_{o}}^{k_{1}}+\sum_{o \in O} \sum_{o^{\prime} \in T_{o}} x_{t_{o} t_{o^{\prime}}}^{k_{2}} e_{t_{o} t_{o^{\prime}}}^{k_{2}} \geq \sum_{i \in O} \sum_{j \in D} x_{i j}^{k_{3}} e_{t_{o} t_{d}}^{k_{3}} \\
& \sum_{m_{u} \in M} \sum_{i, j \in N} x_{i j}^{m_{u}} \leq V^{u} \\
& \sum_{m_{u} \in \mathrm{M}} \sum_{i, j \in N} x_{i j}^{m_{u}} \leq P^{u} \\
& x_{i j}^{m_{u}} \geq 0, m_{u} \in M,(i, j) \in L \\
& e_{o t_{0}}^{k_{1}}, e_{t_{0} t_{o^{\prime}}}^{k_{2}}, e_{t_{o} t_{d^{\prime}}}^{k_{3}}, e_{t_{d} d^{\prime}}^{k_{4}} e_{t_{o}} \text { and } e_{t_{d}} \in\{0,1\}
\end{aligned}
$$

The objective Function (2) minimizes the total system costs. Function (1) is unit cost between $(i, j)$ using transport service $m_{u}$. According to different $m_{u}$ is assigned to the transport, the cost structure changes. Constraint (3) represents the total flow in all possible ranges of the link $(i, j)$ for transport service $m_{u}$ equals the demand. Constraint (4) ensures that each supplier is assigned to a $k_{1}$ link. Constraint (5) ensures that supplier o is assigned to a terminal $e_{t_{o}}$, only if the terminal is open. Constraint (6) ensures that drill site $d$ is assigned to a terminal $e_{t_{d}}$, only if the terminal is open. Constraint (7) ensures that at most one transportation service is chosen for each terminal $e_{t_{0}}$. Constraint (8) ensures that if a link $k_{2}$ exists, the terminal $e_{t_{o}}$ must be open. Constraint (9) ensures that sufficient freight volume is delivered. The intermodal transport services are chosen concerning the cost. Constraint (10) models the consolidation of cargo on long-distance link $\left(t_{o}, t_{d}\right)$. The constraint ensures that sufficient freight volume is delivered. The consolidation transport services are chosen for lower total transport cost. Constraint (11) represents the transportation mode availability. Constraint 
(12) represents the transshipment ability of a terminal can meet the capacity requirement. The domains of the variables are defined in Constraints (13) and (14).

\section{Solution Procedure}

This collaborative intermodal transportation network optimization problem is formulated via a minimum intermodal transport cost model. This formulation is due to the fact that the total transport cost in the objective function is determined by multiplying the unit cost function by the assigned freight quantities. The generalized costs for moving one unit of the commodity are calculated for each transport mode and transshipment in practice. Thus, Equation (1) is non-linear, non-convex and even discontinuous. In this section, we apply a batch strategy to simplify the objective function and develop a hybrid heuristic approach to solve the formulation.

\subsection{Batch Strategy}

$c_{i j}^{k_{n}}\left(x_{i j}^{k_{n}}, d_{i j}^{k_{n}}, S^{u v}\right)(i, j) \in L$, is the unit transportation cost, which is a function of quantity $\left(x_{i j}^{k_{n}}\right)$, distance $\left(d_{i j}^{k_{n}}\right)$ and vehicle capacity $\left(S^{u v}\right)$, there are $v$ kinds of vehicle (including truck and railway) and $k_{n}\left(k_{n} \in K\right)$ transport stages.

In this paper, the rail, road and transshipment costs used in the model are based on the works of Janic (2007, 2008) [20,30] and Bruno F. Santos et al. (2015) [31].

The road transportation operational cost is formulated as

$$
c_{i j}^{k_{n}}\left(x_{i j}^{k_{n}}, d_{i j}^{k_{n}}, S^{u v}\right)=\frac{x_{i j}^{k_{n}} C^{v}\left(d_{i j}^{k_{n}}\right)}{\lambda^{v} S^{u v}}
$$

where, $x_{i j}^{k_{n}}$ is the demand flow between $i$ and $j ; C^{v}\left(d_{i j}^{k_{n}}\right)$ is the unit road transportation operational cost expressed as a function of the road distance $d_{i j}^{k_{n}}$ between $i$ and $j ; \lambda^{v}$ is the load factor of each vehicle (this factor is assumed to be $\lambda^{1}=1, \lambda^{2}=0.91, \lambda^{3}=0.83$ respectively, for the three different vehicle sizes); and $S^{u v}$ is the capacity of each vehicle (here, there are three kinds of capacity $S^{11}=1 \mathrm{TEU} ; S^{12}=2 \mathrm{TEU}$; $\left.S^{13}=2.5 \mathrm{TEU}\right)$. Thus, there are seven types of batch strategies for truck transport, $c_{1}: S^{13} \rightarrow S^{12} \rightarrow S^{11}$; $c_{2}: S^{13} \rightarrow S^{12} ; c_{3}: S^{13} \rightarrow S^{11} ; c_{4}: S^{12} \rightarrow S^{11} ; c_{5}: S^{13} ; c_{6}: S^{12} ; c_{7}: S^{11}$.

Using a regression analysis, Janic (2007) determined that

$$
C^{v}\left(d_{i j}^{k_{n}}\right)=5.456\left(d_{i j}^{k_{n}}\right)^{-0.2773} \text { in /TEU km. }
$$

The rail transportation operational cost is formulated as,

According to Janic (2008), the unit rail transportation operational cost is formulated as

$$
C^{v}\left(d_{i j}^{k_{n}}\right)=0.58 \times\left(W^{v} \times d_{i j}^{k_{n} 2}\right)^{0.74} \text { in / TEU km }
$$

The operational costs are a function of the gross weight of the train $\left(W^{v}\right)$ and the rail distance between terminals $i$ and $j\left(d_{i j}^{k_{n}}\right)$.

$W^{v}=W_{0}^{v}$ (locomotive weight) $+W_{1}^{v}$ (flatcars weight $)+x_{i j} \times 14.3$ (load weight) for $v$ type of train, according to Kim (2016). For the case study, the operating cost was computed assuming a train weight of one locomotive with 20 railcars, one locomotive with 25 railcars and two locomotives with 48 railcars $\left(S^{21}=60 \mathrm{TEU} ; S^{22}=75 \mathrm{TEU} ; S^{23}=140 \mathrm{TEU}\right)$. Thus, there are seven types of batch strategies for rail transport, $c_{1}: S^{23} \rightarrow S^{22} \rightarrow S^{21} ; c_{2}: S^{23} \rightarrow S^{22} ; c_{3}: S^{23} \rightarrow S^{21} ; c_{4}: S^{22} \rightarrow S^{21} ; c_{5}: S^{23} ; c_{6}: S^{22} ; c_{7}: S^{21}$.

The minimum unit cost was found through the batch strategy is as follows (based on Nam Seok $\operatorname{Kim}(2016))$.

Step 1 Create an initial distance $d_{i j}^{k_{n}}$ and vehicle size $v$ for each transport service. 
Step 2 Create choice sets according to $S^{u v}$. The number of sets is $2^{|v|}-1$. For example, if there are three sizes of vehicle $(|v|=3)$, the number of choice sets $C$ is $2^{3}-1=7$.

Step 3 For each kind of vehicle and transport service, estimate $c_{i j}^{k_{n}}\left(x_{i j}^{k_{n}}, d_{i j}^{k_{n}}, S^{u v}\right)$ with the increase in $x_{i j}^{k_{n}}$.

Step 4 For each transport service and choice set, calculate the number of vehicles and remaining TEUs and arrange vehicles with the lowest capacity.

Step 5 For each transport service, estimate ${ }_{i j}^{m_{u}}$.

Step 6 Given quantity $\left(x_{i j}^{k_{n}}\right)$ and distance $\left(d_{i j}^{k_{n}}\right)$, the minimum unit cost and best vehicle arrangement strategies are found.

Step 7 Return to Step 3 when the distance increases to a certain level.

\subsection{Hybrid GA-PSO}

The model is a non-linear integer programming problem. Cheong [32] introduced a Lagrangian relaxation, applying sub gradient optimization to the Lagrangian relaxation to find a good lower bound. However, we expect the computational difficulty of our model to increase rapidly as the number of binary decision variables increases. Hence, we need to explore more specialized solution approaches to have the ability to solve large scale problems. The Genetic Algorithm (GA) is a powerful optimization method that can be used to find a near-optimal result. Specifically, due to the dependence of $\Omega_{i j}^{m_{u}}$ on $x_{i j}^{m_{u}}$, the number of possible route choices for each O/D pair is not simply $x_{i j}^{m_{u}} \times m_{u}$. The numerous combinations of route options and batch strategies in the proposed model make it more complicated. The type of problem needed to estimate the number of cases to assign might be $\sum_{m_{u}} x_{i j}^{m_{u}}$ (a certain quantity) to 9 slots (where $0 \leq m_{u} \leq 9, x_{i j}^{m_{u}}$ is a non-negative integer). Recently, a new evolutionary computation technique, hybrid PSO and GA algorithms has been shown it has better performance than either the GA or the existing algorithms alone (Groothedde et al. 2005 [33]; Hesse and Rodrigue 2004 [34]; Kim and Barnhart 1999 [35]; Kimms 2006 [18]; Limbourg et al. 2009 [36]; Lin et al. 2017 [37]). Hybrid optimization algorithm introduces the concept of the maturing phenomenon in nature mimicked by PSO into the evolution of individuals modeled by GA. In the reproduction and crossover operation of GAs, individuals are reproduced or selected as parents directly to the next generation without any enhancement. However, in nature, individuals will grow up and become more suitable for the environment before producing offspring. To incorporate this phenomenon into GA, PSO that is inspired by the social interaction of knowledge is adopted to enhance the top-ranking individuals in each generation.

In our research, the basic algorithm is based on Kuo et al. [38]. And the detailed GA-PSO operators are: one-quarter of the individuals with the worst fitness values are deleted; Then, one-third of the remaining individuals whose fitness values ranks in the middle are replicated to the next generation to form a new population. Particle velocity and position are updated according to the equation. The crossover operator adopted an elite competition strategy. Two groups are randomly selected, each group has two individuals and individuals with high fitness values are selected to perform crossover, the remaining two individuals perform the PSO algorithm to update the speed and position. Finally, a mutation operator is introduced. The outcome of the GA-PSO approach is a near-optimal solution for transport service and vehicle size choices. The procedure of GA-PSO is shown in Algorithm 1 GA-PSO. The flowchart of GA-PSO is shown in Figure 4. 

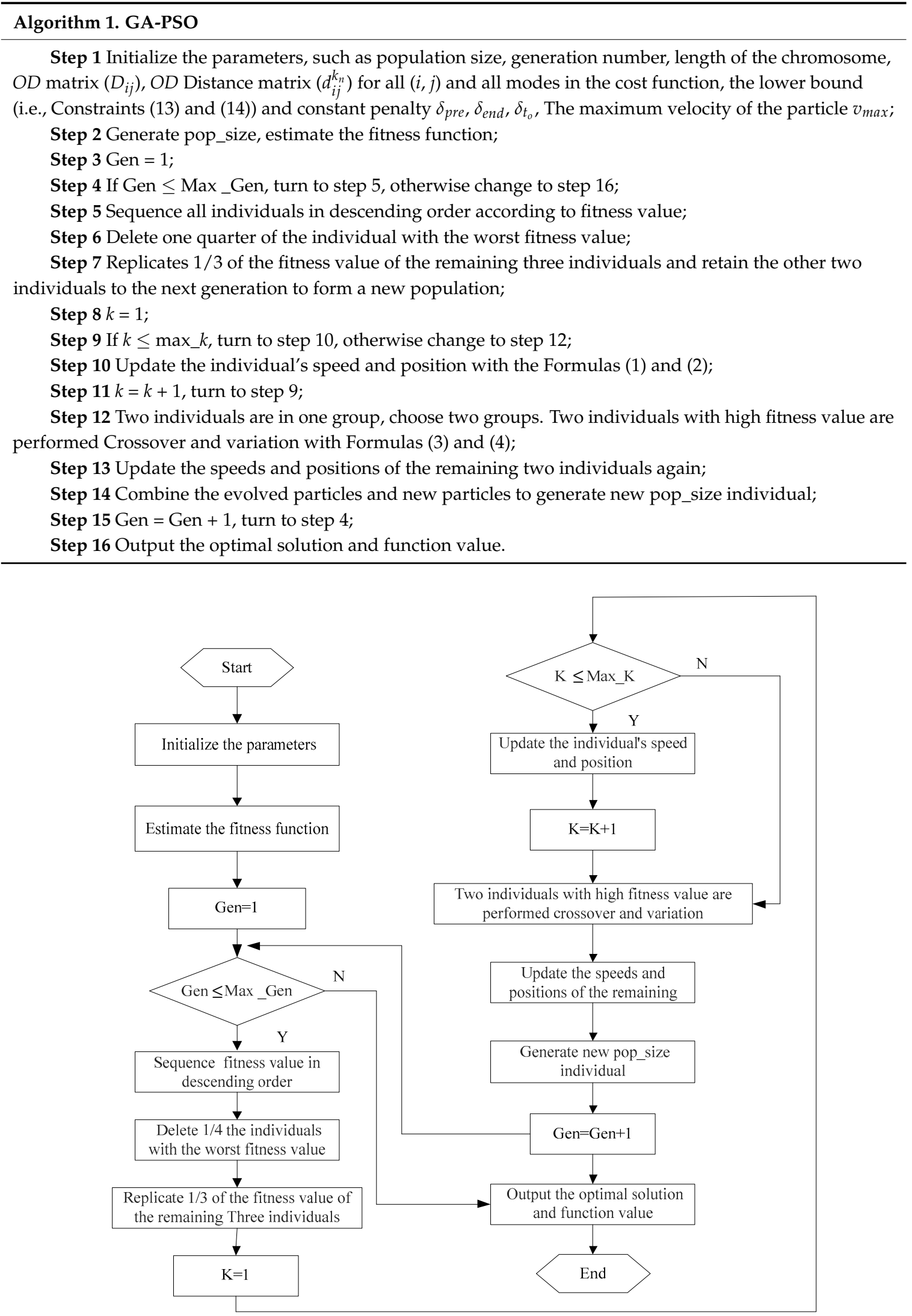

Figure 4. The flowchart of GA-PSO.

The experiments are performed in Matlab 2016 on the computer with Intel Core i7 CPU $2.5 \mathrm{GHz}$ and 16 GB of Ram in Windows 10. To test the performance of the hybrid GA-PSO, we apply it in a 
cluster topology with eight particles (Jérôme E, 2009) [39] and compare the performance with GA and PSO (see Table 3 and Figure 5). The parameters of GA, PSO and GA-PSO are shown below.
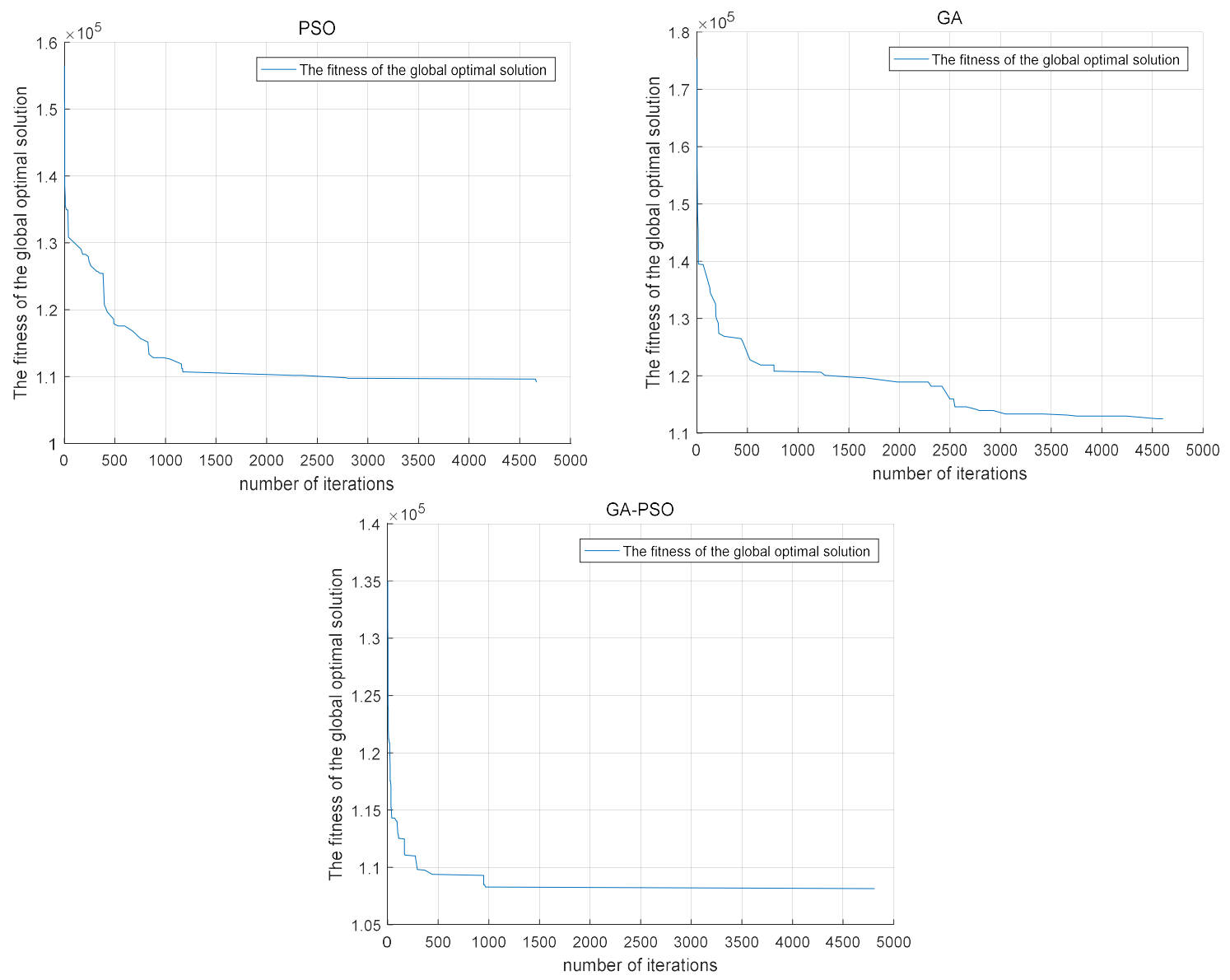

Figure 5. The fitness of the global optimal solution vs. the number of iteration.

GA: The crossover probability and the mutation probability were set to 0.7 and 0.07 , respectively. The population size was set at 300 and 500 offspring. The evolutionary process was kept running until no improvements were made in the objective function for 10 consecutive generation cycles (i.e., $5000 \times 10$ offsprings).

PSO: The numbers of particles and generations were set to be 60 and 500, respectively. Also, the maximum velocity was set as 2 . The inertia weight factor $w$ was also set as a time-variant linear function decreasing with the increase of the number of generations where at any generation $i$.

$\mathrm{w}=0.4+0.8 \times($ number of generations- $i) /($ number of generations -1$)$

GA-PSO: Initial value is set to 0.8 . The relaxation time scale is set to 1 and the discrete-time step 0.1 is used. 300 individuals are randomly generated in a population, that is, There are $20 \times 20$ genes in each individual and the initial weights are uniform random values between -8 and 8 . The evolution is processed for 5000 iterations and is repeated for 10 runs.

The performance of the different algorithms was compared using three criteria: (1) the percentage of success, as represented by the number of trials required for the objective function to reach its known target value; (2) the processing time to reach the optimal target value; (3) the average value of the solution obtained in all trials.

Among the results obtained using PSO, GA and hybrid GA-PSO in MATLAB, GA performed more poorly than the other two algorithms. The success rate is $20 \%$, the processing time is $25 \mathrm{~s}$. The Upon applying the hybrid GA-PSO, the results improved significantly compared to those obtained using the GA and PSO, in terms of both the minimum cost, the success rate and the processing time 
(Table 3). Figure 5 shows the fitness of the global optimal solution versus the number of iteration on these three kinds of algorithms. The iteration number of hybrid GA-PSO is 1000, which performs better than GA, while the same as PSO.

Table 3. Performance Comparisons for GA, PSO and GA-PSO.

\begin{tabular}{cccc}
\hline Algorithm & Minimum Cost (\$) & \% Success Rate & Processing Time (s) \\
\hline GA & 116,520 & 20 & 25 \\
PSO & 110,620 & 20 & 20 \\
GA-PSO & 108,960 & 50 & 16 \\
\hline
\end{tabular}

\section{Scenario Studies}

An intermodal freight transport network is established to cover the major cities which are suppliers of oil and gas equipment and Crexpress terminals along "The silk road." Eight nodes are considered in the network (Figure 6). Wuhan and Changsha are chosen as the initial nodes because they are the major cities where oil and gas equipment enterprises locate. Manzhouli and Alashankou are the destination nodes, which are two main inland ports, where Crexpress pass and linked to Europe and central Asia. Zhengzhou and Chongqing are initial terminals where freight transfer and consolidate, Harbin and Urumchi are the destination terminals near the inland ports. The distance for each link is estimated from Geographic Information Systems (GIS). The estimates of the OD set demands (container flows) are based on an investigation for China Oil and Gas Industry Association and twenty-four oil drilling equipment companies located in Wuhan and Changsha (Table 4). The Crexpress Coordination Committee was established to make freight to be transported integrated into a platform. Here we assume that each transshipment terminal that located in the different provinces is serviced by one freight forwarder.

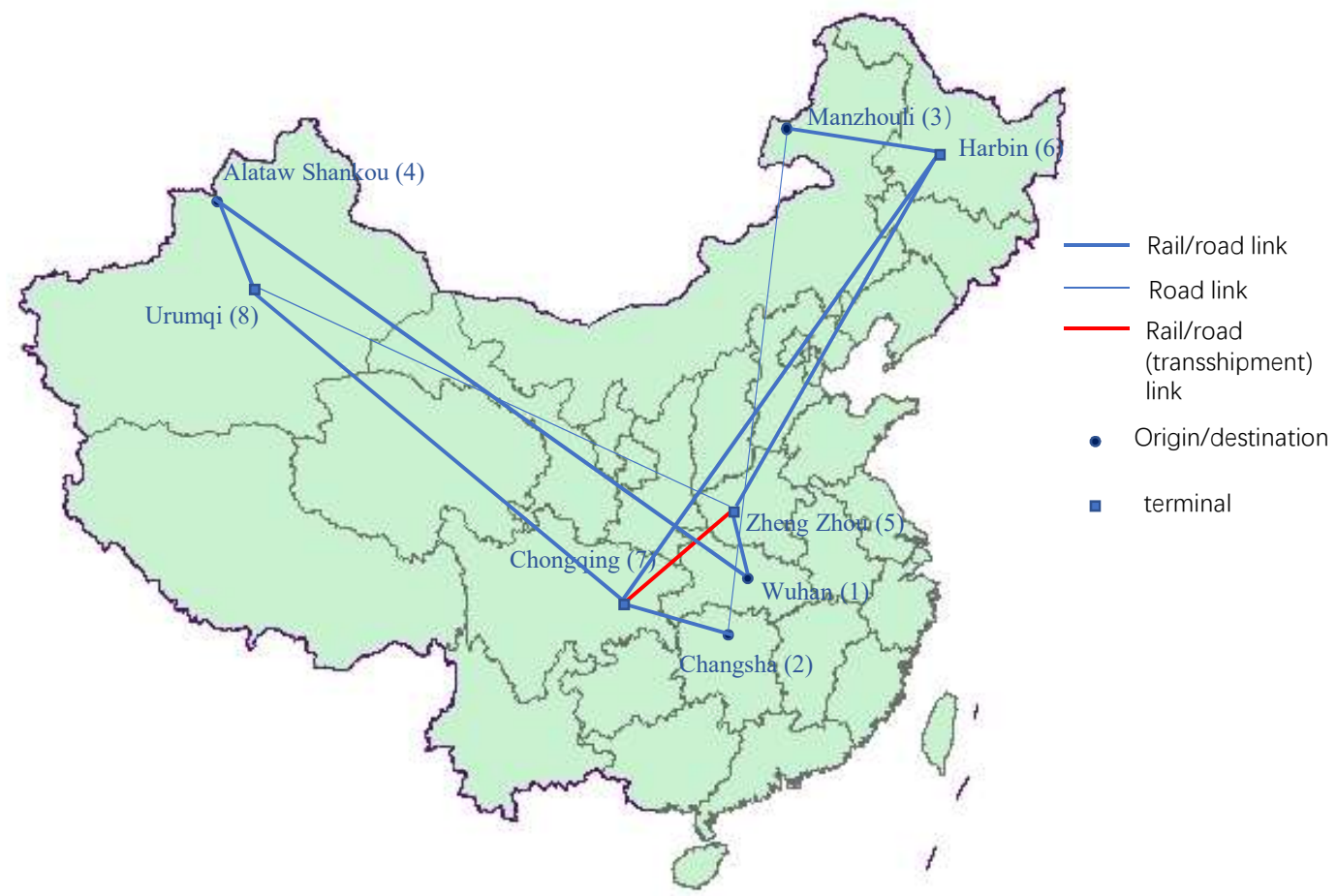

Figure 6. Intermodal freight transport network of oil and gas drilling equipment. 
Table 4. Oil and gas equipment O-D demand.

\begin{tabular}{ccccc}
\hline Corporations & Products & Origin & Destination & $\begin{array}{c}\text { Container Flows } \\
\text { (TEU/week) }\end{array}$ \\
\hline $1,6,7,8,13,15$ & Mud pumps & Wuhan & Manzhouli & 152 \\
$3,4,12,16$ & Combined drill bit & Wuhan & Alashankou & 13 \\
$2,4,5,6,14$ & Travelling block & Wuhan & Manzhouli & 124 \\
9,11 & Completion Rig & Wuhan & Manzhouli & 29 \\
$1,2,3,7,10$ & Combined drill bit & Wuhan & Alashankou & 34 \\
$18,21,22$ & Drill Pad & Changsha & Manzhouli & 33 \\
20,22 & Shale shakers & Changsha & Alashankou & 43 \\
$17,18,23,24$ & Mud pumps & Changsha & Alashankou & 149 \\
$19,20,23$ & Drill bit & Changsha & Alashankou & 16 \\
\hline
\end{tabular}

The current container flows for Wuhan-Manzhouli (1-3), Wuhan-Alashankou (1-4), Changsha-Manzhouli (2-3) and Changsha-Alashankou (2-4) are 305, 47, 208 and 33 TEUs respectively. On each connection, the daily service capacity of road and railway is 400, 150 TEUs (considering the number of trucks and railway vans). Transshipment cost rate (dollar/ton-movement) is estimated according to previous research, 2.923\$ (Shuaian Wang and Qiang Meng [40]; Black et al. [41]; Brown and Hatch [42]; De Jong et al. [43]).

Tables $5-8$ show the path selection and vehicle arrangement strategies for the oil field equipment that minimized the total logistics cost. The first column is for $O D(i, j)$ pairs. In the second column, $m_{u}$ is defined in Figure 2 and assigned transshipment terminals for different $O D$ showed in the second column. Different modes of transport between two nodes and vehicle arrangement strategies are shown in the fifth column. Five scenarios are tested, current requirements with limited capacity (see Table 5), current requirements with infinite capacity (see Table 6), double requirements in Origin 1 with infinite capacity and double requirements in Origin 2 with infinite capacity (see Table 7), double requirements in Origin 1 and Origin 2 with infinite capacity (see Table 8).

For Scenario 1, a single highway system $\left(m_{u}=1\right)$ is selected for the link $(1,4)$ and the vehicle scheduling strategy is 2.5 TEU-truck $\left(c_{5}\right)$. The main reason for all 305 TEUs being allocated to the highway transportation system is the limited transport capacity of railway transport (the railway is 150TEUs), or that the railway distance between Wuhan and Alashankou is relatively long. The length of the railway intermodal transport system $\left(m_{u}=2\right)$ is $4063 \mathrm{~km}$, while the road transportation $\left(m_{u}=1\right)$ is only $3830 \mathrm{~km}$. Thus, the cost saving obtained by using the intermodal transportation system is greatly reduced due to the extra distance. In addition, the QES occurring for link $(1,4)$ are not sufficient to transfer 305 TEUs from unimodal road transport $\left(m_{u}=1\right)$ to other intermodal transport systems $\left(m_{u}=2-9\right)$. Link $(1,3)$ and $(2,3)$ exhibit the same situation, in that the quantity of freight is not sufficient to achieve QES. Thus, unimodal road transport is the best option for link $(1,3)$ and $(2,3)$. 208TEUs on the link $(2,4)$ pass terminals (7) (8)and delivered by intermodal transport modes, which embody the economies of scale. 44 TEUs are delivered through service 2 and 164 TEUs are delivered through service 4 .

The $O D$ flow in Scenario 2 is the same but the capacity is infinite. The infinite capacity indicates that intermodal transport service can be used if they are more cost-effective than the unimodal transport. Meanwhile, infinite capacity would result in a much larger search space for feasible solutions, which lead to better solutions. The transport service between $(1,4), 279$ TEU is shifted to truck-rail-rail intermodal transport. As we mentioned, in scenario 1, 305 TEUs is assigned to a truck only device because of the limited capacity. 208TEUs in scenario 2 are transported through service 1, 2, 4. Overall, 1,068,852 USD cost saving (saving 80,808 USD) is achieved. 
Table 5. Transport service and vehicle arrangement in scenario 1.

\begin{tabular}{|c|c|c|c|c|}
\hline \multirow{4}{*}{$\operatorname{Link}(i, j)$} & \multirow{4}{*}{$\begin{array}{l}\text { Transport } \\
\text { Service } m_{u}\end{array}$} & \multirow{4}{*}{ Demand } & \multirow{4}{*}{ Terminals } & Transport mode and vehicle arrangement \\
\hline & & & & (1)(2)(3)(4) initial and end nodes \\
\hline & & & & (5)(6)(7) (8) terminals \\
\hline & & & & $\begin{array}{l}c_{1}-c_{7}: \text { vehicle and rail arrangement strategies in } \\
\text { different transport stage } k_{n}\end{array}$ \\
\hline \multicolumn{5}{|c|}{ Scenario 1 (current requirements with limited cacpacity): Total cost $=1,149,660$ USD } \\
\hline$(1,3)$ & 1 & 47 & & (1) $1 \frac{\operatorname{truck}\left(c_{2}\right)}{k_{1}}$ (2) \\
\hline$(1,4)$ & 1 & 305 & & (1) $\frac{\operatorname{tr}-u c k\left(c_{5}\right)}{c k_{1}}$ (4) \\
\hline$(2,3)$ & 1 & 33 & & (2) $\frac{\operatorname{truck}\left(c_{1}\right)}{k_{1}}$ (3) \\
\hline \multirow{2}{*}{$(2,4)$} & 2 & 44 & (7) 8 & (2) $\frac{\operatorname{tnruck}\left(c_{1}\right)}{k_{1}}$ (7) $\frac{\text { rail }\left(c_{2}\right)}{k_{2}}$ (8) $\frac{\operatorname{truck}\left(c_{1}\right)}{k_{3}}$ (4) \\
\hline & 4 & 164 & (7) 8 & (2) $\frac{\operatorname{truck}\left(c_{1}\right)}{k_{1}}(7) \frac{\operatorname{rail}\left(c_{2}\right)}{k_{2}}$ (8) $\frac{\operatorname{rail}\left(c_{5}\right)}{k_{3}}$ (4) \\
\hline
\end{tabular}

Table 6. Transport service and vehicle arrangement in scenario 2.

\begin{tabular}{|c|c|c|c|c|}
\hline \multirow{4}{*}{ Link $(i, j)$} & \multirow{4}{*}{$\begin{array}{l}\text { Transport } \\
\text { service } m_{u}\end{array}$} & \multirow{4}{*}{ Demand } & \multirow{4}{*}{ Terminals } & Transport mode and vehicle arrangement \\
\hline & & & & (1)(2)(3)(4) initial and end nodes \\
\hline & & & & (5)(6)(7) (8) terminals \\
\hline & & & & $c_{1}-c_{7}:$ vehicle and rail arrangement strategies $k_{n}$ \\
\hline \multicolumn{5}{|c|}{ Scenario 2 (current requirements with infinite ccapacity): Total cost $=1,068,852$ USD } \\
\hline$(1,3)$ & 1 & 47 & & (1) $\frac{\operatorname{truck}\left(c_{2}\right)}{k_{1}}(2)$ \\
\hline \multirow[t]{2}{*}{$(1,4)$} & 1 & 26 & & (1) $\frac{\operatorname{truck}\left(c_{5}\right)}{k_{1}}(4)$ \\
\hline & 2 & 279 & (5) (8) & (1) $\frac{\operatorname{truck}\left(c_{1}\right)}{k_{1}}(5) \frac{\operatorname{rail}\left(c_{2}\right)}{k_{2}}$ (6) $\frac{\operatorname{truck}\left(c_{5}\right)}{k_{3}}(4)$ \\
\hline$(2,3)$ & 1 & 33 & & (2) $\frac{\operatorname{truckc}\left(c_{1}\right)}{k_{1} 5}(3)$ \\
\hline \multirow[t]{3}{*}{$(2,4)$} & 1 & 28 & (7) 8 & (2) $\frac{\operatorname{truck}\left(c_{2}\right)}{k_{1}}$ (4) \\
\hline & 2 & 48 & (7) (8) & \multirow{2}{*}{$\begin{array}{l}\text { (2) } \frac{\operatorname{truck}\left(c_{1}\right)}{k_{1}} \text { (7) } \frac{\operatorname{rail}\left(c_{2}\right)}{k_{2}} \text { (8) } \frac{\operatorname{truck}\left(c_{1}\right)}{k_{3}} \text { (4) } \\
\text { (2) } \frac{\operatorname{rail}\left(c_{2}\right)}{k_{1}} \text { (1)(7) } \frac{\operatorname{truck}\left(c_{1}\right)}{k_{1}} \text { (8) } \frac{\operatorname{rail}\left(c_{5}\right)}{k_{3}} \text { (4) }\end{array}$} \\
\hline & 4 & 132 & (7) 8 & \\
\hline
\end{tabular}

The demand in scenario 3 doubles in origin 1 with the unlimited capacity and the demand remains the same in origin 2 . While the demand in scenario 4 doubles in origin 2 with the unlimited capacity and the demand remains the same in origin 1. As cooperation is assumed between Crepresses in this situation, freight consolidated in different origin terminals can be transit. For link $(2,4)$, freight consolidates in terminal 7 in scenario 1 and 2 are shifted to terminal 7 , then 5 , which means the freight flows from $(1,4)$ and $(2,4)$ are consolidated in terminal 5 . The similar situation happens in scenario 4 . For link $(1,4)$, freight consolidates in terminal 5 , then 7 . The economies of scale can be realized through cooperation between Crepresses.

Comparing Scenario 5 with Scenario 2, when the demand doubles with infinite capacity, the total cost of Scenario $5(C=1,889,775)$ is less than 2 times that of Scenario $2(C=1,068,852)$. For the links $(1,3)$ and $(2,3)$, the transport service changed from unimodal $\left(m_{u}=1\right)$ to intermodal $\left(m_{u}=3,2\right)$. It indicates that the advantage of economies of scale overcomes the disadvantage of the detours. With the increase in freight quantity, advantages of intermodal transport are much obvious. 
Table 7. Transport service and vehicle arrangement in scenario 3 and 4.

\begin{tabular}{|c|c|c|c|c|}
\hline \multirow[b]{2}{*}{$\operatorname{Link}(i, j)$} & \multirow[b]{2}{*}{$\begin{array}{l}\text { Transport } \\
\text { Service } m_{u}\end{array}$} & \multirow[b]{2}{*}{ Demand } & \multirow[b]{2}{*}{ Terminals } & Transport mode and vehicle arrangement \\
\hline & & & & $\begin{array}{l}c_{1}-c_{7}: \text { vehicle and rail arrangement } \\
\text { strategies in } k_{n}\end{array}$ \\
\hline \multicolumn{5}{|c|}{ Scenario 3 (double requirements in Origin 1 with infinite capacity): Total cost $=1,474,016$ USD } \\
\hline$(1,3)$ & 3 & 94 & & (1) $\frac{\operatorname{truck}\left(c_{5}\right)}{k_{1}}(5) \frac{\operatorname{rail}\left(c_{1}\right)}{k_{2}}(7) \frac{\operatorname{rail}\left(c_{1}\right)}{k_{2}}$ (3) \\
\hline \multirow[t]{2}{*}{$(1,4)$} & 5 & 582 & (5) (6) & (1) $\frac{\operatorname{rail}\left(c_{4}\right)}{k_{1}}$ (5) $\frac{\operatorname{rail}\left(c_{1}\right)}{k_{2}}$ (6) $\frac{\operatorname{rail}\left(c_{4}\right)}{k_{3}}$ (4) \\
\hline & 1 & 32 & & (1) $\frac{\operatorname{truck}\left(c_{5}\right)}{k_{1}}(4)$ \\
\hline$(2,3)$ & 2 & 33 & (7) (6) & (2) $\frac{\operatorname{truck}\left(c_{2}\right)}{k_{1}}$ (5) $\frac{\operatorname{rail}\left(c_{1}\right)}{k_{2}}$ (6) $\frac{\operatorname{truck}\left(c_{1}\right)}{k_{3}}$ (3) \\
\hline \multirow{2}{*}{$(2,4)$} & 7 & 188 & (7)(5) 8 & \multirow{2}{*}{$\begin{array}{l}\text { (2) } \frac{\operatorname{truck}\left(c_{2}\right)}{k_{1}} \text { (7) } \frac{\operatorname{rail}\left(c_{4}\right)}{k_{2}} \text { (5) } \frac{\operatorname{rail}\left(c_{1}\right)}{k_{3}} \text { (6) } \frac{\operatorname{rail}\left(c_{4}\right)}{k_{4}}(4) \\
\text { (2) } \frac{\operatorname{ruck}\left(c_{1}\right)}{k_{1}} \text { (7) } \frac{\operatorname{rail}\left(c_{2}\right)}{k_{2}} \text { (8) } \frac{\operatorname{rail}\left(c_{5}\right)}{k_{3}} \text { (4) }\end{array}$} \\
\hline & 3 & 20 & (7) 8 & \\
\hline \multicolumn{5}{|c|}{ Scenario 4 (double requirements in Origin 2 with infinite capacity): Total cost $=1,395,204$ USD } \\
\hline$(1,3)$ & 5 & 94 & (5) (6) & (1) $\frac{\operatorname{rail}\left(c_{4}\right)}{k_{1}}$ (5) $\frac{\operatorname{rail}\left(c_{1}\right)}{k_{2}}$ (6) $\frac{\operatorname{rail}\left(c_{4}\right)}{k_{3}}$ (3) \\
\hline \multirow[t]{2}{*}{$(1,4)$} & 1 & 9 & & (1) $\frac{\operatorname{truck}\left(c_{5}\right)}{k_{1}}$ (4) \\
\hline & 8 & 196 & (5)(7)(6) & (1) $\frac{\operatorname{rail}\left(c_{5}\right)}{k_{1}}$ (5) $\frac{\operatorname{rail}\left(c_{1}\right)}{k_{2}}(7) \frac{\operatorname{rail}\left(c_{2}\right)}{k_{3}}$ (8) $\frac{\operatorname{truck}\left(c_{1}\right)}{k_{4}}$ (4) \\
\hline$(2,3)$ & 2 & 66 & (5) (6) & (2) $\frac{\operatorname{truck}\left(c_{2}\right)}{k_{1}}$ (5) $\frac{\operatorname{rail}\left(c_{1}\right)}{k_{2}}$ (6) $\frac{\operatorname{truck}\left(c_{1}\right)}{k_{3}}$ (3) \\
\hline \multirow{3}{*}{$(2,4)$} & 2 & 382 & \multirow{3}{*}{$\begin{array}{l}(7) 8 \\
(7)(8)\end{array}$} & \multirow{3}{*}{$\begin{array}{l}\text { (2) } \frac{\operatorname{truck}\left(c_{1}\right)}{k_{1}}(7) \frac{\operatorname{rail}\left(c_{2}\right)}{k_{2}}(8) \frac{\operatorname{truck}\left(c_{1}\right)}{k_{3}}(4) \\
\text { (2) } \frac{\operatorname{rail}\left(c_{5}\right)}{k_{1}}(7) \frac{\operatorname{rail}\left(c_{2}\right)}{k_{2}}(8) \frac{\operatorname{truck}\left(c_{1}\right)}{k_{3}} \text { (4) } \\
\text { (7) } \frac{\operatorname{truck}\left(c_{1}\right)}{k_{1}} \text { (4) }\end{array}$} \\
\hline & 4 & 25 & & \\
\hline & 1 & 9 & & \\
\hline
\end{tabular}

Table 8. Transport service and vehicle arrangement in scenario 5.

\begin{tabular}{|c|c|c|c|c|}
\hline \multirow{4}{*}{ Link $(i, j)$} & \multirow{4}{*}{$\begin{array}{c}\text { Transport } \\
\text { service } m_{u}\end{array}$} & \multirow{4}{*}{ Demand } & \multirow{4}{*}{ Terminals } & Transport mode and vehicle arrangement \\
\hline & & & & (1)(2)(3)(4) initial and end nodes \\
\hline & & & & (5) (6) (7) (8) terminals \\
\hline & & & & $c_{1}-c_{7}:$ vehicle and rail arrangement strategies $k_{n}$ \\
\hline \multicolumn{5}{|c|}{ Scenario 5 (double requirements in Origin 1 and Origin 2 with infinite capacity): Total cost $=1,889,775$ USD } \\
\hline$(1,3)$ & 3 & 94 & (5) (6) & (1) $\frac{\operatorname{truck}\left(c_{2}\right)}{k_{1}}$ (5) $\frac{\operatorname{rail}\left(c_{1}\right)}{k_{2}}$ (6) $\frac{\text { rail }\left(c_{4}\right)}{k_{3}}$ (3) \\
\hline \multirow[t]{2}{*}{$(1,4)$} & 5 & 582 & (5) (6) & (1) $\frac{\operatorname{rail}\left(c_{4}\right)}{k_{1}}$ (5) $\frac{\operatorname{rail}\left(c_{1}\right)}{k_{2}}$ (6) $\frac{\operatorname{rail}\left(c_{4}\right)}{k_{3}}$ (4) \\
\hline & 1 & 32 & & (1) $\frac{\operatorname{truck}\left(c_{5}\right)}{k_{1}}(4)$ \\
\hline$(2,3)$ & 2 & 66 & (5)(6) & (2) $\frac{\operatorname{truck}\left(c_{2}\right)}{k_{1}}$ (5) $\frac{\operatorname{rail}\left(c_{1}\right)}{k_{2}}$ (6) $\frac{\operatorname{truck}\left(c_{1}\right)}{k_{2}}$ (3) \\
\hline \multirow{2}{*}{$(2,4)$} & 2 & 367 & (7) 8 & (2) $\frac{\operatorname{truck}\left(c_{1}\right)}{k_{1}}$ (7) $\frac{\operatorname{rail}\left(c_{1}\right)}{k_{2}}$ (8) $\frac{\operatorname{truck}\left(c_{1}\right)}{k_{3}}$ (4) \\
\hline & 3 & 49 & (7) 8 & (2) $\frac{\operatorname{truck}\left(c_{1}\right)}{k_{1}}$ (7) $\frac{\operatorname{rail}\left(c_{2}\right)}{k_{2}}$ (8) $\frac{\operatorname{rail}\left(c_{5}\right)}{k_{3}}$ (4) \\
\hline
\end{tabular}

In summary, the scenario studies show the effect of economies of scale on freight transportation planning, includes consolidation strategy, transport mode and vehicle arrangement. More specifically, we can find that one unit modal shift in quantity in an arc could result in a complete change of terminal choice, route choice and vehicle arrangement. In other words, the scenario outcomes are, firstly, trade-off among distance diseconomies of scale on pre-/post- haulage as well as economies of scale on long-distance. Secondly, different freight demand leads to a different collaborative freight network (consolidation strategy) and optimal batch strategy. Also, increased demand made it possible to use larger capacity vehicles, which is related to QES and VES.

\section{Conclusions}

Collaborative freight planning represents an efficient way to obtain a sustainable transportation system. In this study, a collaborative intermodal transportation network is designed, which is 
applied in oil and gas equipment industry. As the diversity of product size and shipment volume provides an opportunity to realize economies of scale through freight consolidation, freight forwarders collaboratively plan for the entire freight transportation network by determining their corridor and vehicle arrangement strategies in pre-haulage, transshipment link, main-haulage and post-haulage, also accounting for the handling capacity at competitive terminals. To solve this complex integration optimization problem, the MTC model is formulated with non-linear, discontinuous and non-convex transport cost objective function. As the calculation time of the large-size instance is long, a hybrid GA-PSO algorithm embedded in a batch strategy is developed to find solutions for the transport service and vehicle arrangement strategy. Compared with GA and PSO, the result shows that the hybrid GA-PSO method was generally found to perform better than other algorithms in terms of success rate and processing time, while being slightly better in terms of the rate of convergence. Also, five scenarios of transportation requirement are tested on Crexpresses, based on the aggregate data from transportation agencies and disaggregate data from independent oil and gas drilling companies. As a result, transport service $\left(m_{u}\right)$ and vehicle arrangement strategies $(c)$ of oil and gas equipment are given at the same time, which shows the effect of the designed collaborative transport network and MTC model. This research might contribute to the tactical freight network design and optimization.

In our research, freight forwarder representing the local government acts as a third-party logistics provider to make freight transport planning. From a practical standpoint, collaborative freight planning might solve the urgent problem of how to realize freight consolidation in inland cities to achieve a sustainable intermodal transport network, where freight transportation demand is specific and locates in a remote place.

For future research, we will test our method in a large-scale network, also consider the dynamic demands in the service network for collaborative intermodal freight transport and explore other influential factors on service/corridor choice and vehicle arrangement strategies.

Author Contributions: Conceptualization, Q.S.; Resources, Y.W.; Software, Z.D.; Supervision, Y.W.; Writing-original draft, D.L.

Funding: The paper was based on a research project financed by the National Natural Science Foundation of China (Grant No. 61806021, 71701022), the Humanities and Social Sciences Project of Education Ministry (Grant No. 15YJCZH093), the Social Science Fund Project in Shaanxi Province (Grant No. 2014P08), the Theoretical and Practical Research Projects in Shaanxi Province (Grant No. 2018Z158). This research was also supported by the basic scientific research funds of central universities (Grant No. 310823160645, 300102238401, 300102238605, 300102238655).

Conflicts of Interest: The authors declare that there are no conflicts of interest regarding the publication of this paper.

\section{References}

1. Hoeffler, S.; Keller, K.L. Building brand equity through corporate societal marketing. J. Public Policy Mark. 2002, 21, 78-89. [CrossRef]

2. McGinnis, M.A. International Shipper attitudes toward freight transportation choice: A factor analytic study. J. Phys. Distrib. Manag. 1979, 10, 25-34.

3. Álvarez-Sanjaime, Ó.; Cantos-Sánchez, P.; Moner-Colonques, R.; Sempere-Monerris, J.J. Competition and horizontal integration in maritime freight transport. Transp. Res. Part E Logist. Transp. Rev. 2013, 51, 67-81. [CrossRef]

4. Cruijssen, F.C.A.M.; Salomon, M. Empirical Study: Order Sharing between Transportation Companies May Result in Cost Reductions between 5 to 15 Percent; CentER Discussion Paper; 2004; Volume 80, pp. 1-22. Available online: https:/ / papers.ssrn.com/sol3/papers.cfm?abstract_id=607062 (accessed on 14 February 2019).

5. Krajewska, M.A.; Kopfer, H.; Laporte, G.; Ropke, S.; Zaccour, G. Horizontal cooperation among freight carriers: Request allocation and profit sharing. J. Oper. Res. Soc. 2008, 59, 1483-1491. [CrossRef]

6. Verdonck, L.; Caris, A.N.; Ramaekers, K.; Janssens, G.K. Collaborative logistics from the perspective of road transportation companies. Transp. Rev. 2013, 33, 700-719. [CrossRef] 
7. Agarwal, R.; Ergun, Ö. Network design and allocation mechanisms for carrier alliances in liner shipping. Oper. Res. 2010, 58, 1726-1742. [CrossRef]

8. Chen, H. Combinatorial clock-proxy exchange for carrier collaboration in less than truckload transportation. Transp. Res. Part E Logist. Transp. Rev. 2016, 91, 152-172. [CrossRef]

9. Dai, B.; Chen, H.; Yang, G. Price-setting based combinatorial auction approach for carrier collaboration with pickup and delivery requests. Oper. Res. 2014, 14, 361-386. [CrossRef]

10. Hernández, S.; Peeta, S.; Kalafatas, G. A less-than-truckload carrier collaboration planning problem under dynamic capacities. Transp. Res. Part E Logist. Transp. Rev. 2011, 47, 933-946. [CrossRef]

11. Liu, P.; Wu, Y.; Xu, N. Allocating collaborative profit in less-than-truckload carrier alliance. J. Serv. Sci. Manag. 2010, 3, 143-149. [CrossRef]

12. Wang, X.; Kopfer, H. Collaborative transportation planning of less-than-truckload freight. OR Spectr. 2014, 36, 357-380. [CrossRef]

13. Christiansen, M.; Fagerholt, K.; Nygreen, B.; Ronen, D. Maritime transportation. Handb. Oper. Res. Manag. Sci. 2007, 14, 189-284.

14. Bektaş, T.; Crainic, T.G.; Morency, V. Improving the performance of rail yards through dynamic reassignments of empty cars. Transp. Res. Part C Emerg. Technol. Morency 2009, 17, 259-273. [CrossRef]

15. Caris, A.; Macharis, C.; Janssens, G.K. Decision support in intermodal transport: A new research agenda. Comput. Ind. 2013, 64, 105-112. [CrossRef]

16. SteadieSeifi, M.; Dellaert, N.P.; Nuijten, W.; van Woensel, T.; Raoufi, R. Multimodal freight transportation planning: A literature review. Eur. J. Oper. Res. 2014, 233, 1-15. [CrossRef]

17. Agamez-Arias, A.D.M.; Moyano-Fuentes, J. Intermodal transport in freight distribution: A literature review. Transp. Rev. 2017, 37, 782-807. [CrossRef]

18. Kimms, A. Economies of scale in hub \& spoke network design models: We have it all wrong. In Perspectives on Operations Research: Essays in Honor of Klaus Neumann; Morlock, M., Schwindt, C., Trautmann, N., Zimmer-mann, J., Eds.; Deutscher Universitätsverlag: Wiesbaden, Germany, 2006.

19. Racunica, I.; Wynter, L. Optimal location of intermodal freight hubs. Transp. Res. Part B Methodol. 2005, 39, 453-477. [CrossRef]

20. Janic, M. Modelling the full costs of an intermodal and road freight transport network. Transp. Res. Part D Transp. Environ. 2007, 12, 33-44. [CrossRef]

21. Kim, N.S.; Park, B.; Lee, K.-D. A knowledge based freight management decision support system incorporating economies of scale: Multimodal minimum cost flow optimization approach. Inf. Technol. Manag. 2016, 17, 81-94. [CrossRef]

22. Zinn, W.; Parasuraman, A. Scope and intensity of logistics-based strategic alliances: A conceptual classification and managerial implications. Ind. Mark. Manag. 1997, 26, 137-147. [CrossRef]

23. Gulati, R.; Nohria, N.; Zaheer, A. Strategic networks. Strateg. Manag. J. 2000, 21, 203-215. [CrossRef]

24. Kreutzberger, E.D. Distance and time in intermodal goods transport networks in Europe: A generic approach. Transp. Res. Part A 2008, 42, 973-993. [CrossRef]

25. Konings, J.W. Integrated centres for the transshipment, storage, collection and distribution of goods: A survey of the possibilities for a high-quality intermodal transport concept. Transp. Policy 1996, 3, 3-11. [CrossRef]

26. Kim, N.S.; van Wee, B. The relative importance of factors that influence the break-even distance of intermodal freight transport systems. J. Transp. Geogr. 2011, 19, 859-875. [CrossRef]

27. Resor, R.; Blaze, J.; Morlok, E. Short-haul rail intermodal: Can it compete with trucks? Transp. Res. Rec. J. Transp. Res. Board 2004, 1873, 45-52. [CrossRef]

28. Tavasszy, L.; de Jong, G. Modelling Freight Transport; Elsevier: Amsterdam, The Netherlands, 2013.

29. Jara-Diaz, S.R.; Basso, L.J. Transport Cost Functions, Network Expansion and Economies of Scope. Transp. Res. Part E Logist. Transp. Rev. 2003, 39, 271-288. [CrossRef]

30. Janic, M. An assessment of the performance of the European long intermodal freight trains (LIFTS). Transp. Res. Part A Policy Pract. 2008, 42, 1326-1339. [CrossRef]

31. Santos, B.F.; Limbourg, S.; Carreira, J.S. The impact of transport policies on railroad intermodal freight competitiveness-The case of Belgium. Transp. Res. Part D Transp. Environ. 2015, 34, 230-244. [CrossRef]

32. Cheong, M.L.; Bhatnagar, R.; Graves, S.C. Logistics network design with supplier consolidation hubs and multiple shipment options. J. Ind. Manag. Optim. 2007, 3, 51-69. 
33. Groothedde, B.; Ruijgrok, C.; Tavasszy, L. Towards collaborative, intermodal hub networks: A case study in the fast moving consumer goods market. Transp. Res. Part E Logist. Transp. Rev. 2005, 41, 567-583. [CrossRef]

34. Hesse, M.; Rodrigue, J.-P. The transport geography of logistics and freight distribution. J. Transp. Geogr. 2004, 12, 171-184. [CrossRef]

35. Kim, D.; Barnhart, C. Transportation service network design: Models and algorithms. In Computer-Aided Transit Scheduling; Lecture notes in economics and mathematical systems 471; Wilson, N.H.M., Ed.; Springer: Berlin, Germany, 1999; pp. 259-283.

36. Limbourg, S.; Jourquin, B. Optimal rail-road container terminal locations on the European network. Transp. Res. Part E Logist. Transp. Rev. 2009, 45, 551-563. [CrossRef]

37. Lin, Y.-K.; Huang, C.-F.; Liao, Y.-C.; Yeh, C.-C. System reliability for a multistate intermodal logistics network with time windows. Int. J. Prod. Res. 2017, 55, 1957-1969. [CrossRef]

38. Kuo, R.J.; Wang, M.J.; Huang, T.W. An application of particle swarm optimization algorithm to clustering analysis Soft Computing-A Fusion of Foundations. Methodol. Appl. 2011, 15, 533-542.

39. Onwunalu, J.E.; Durlofsky, L.J. Application of a particle swarm optimization algorithm for determining optimum well location and type. Comput. Geosci. 2010, 14, 183-198. [CrossRef]

40. Wang, S.; Meng, Q. Schedule design and container routing in liner shipping. Transp. Res. Rec. J. Transp. Res. Board 2011, 2222, 25-33. [CrossRef]

41. Black, I.; Seaton, R.; Ricci, A.; Enei, R. Final Report for RECORDIT: Actions to Promote Intermodal Transport; UK, 2003; Available online: http:/ / www.transport-research.info/sites/default/files/project/documents / 20060727_155159_96220_RECORDIT_Final_Report.pdf (accessed on 14 February 2019).

42. Brown, T.A.; Hatch, A.B. The Value of Rail Intermodal to the US Economy; Association of American Railroads: Washington, DC, USA, 2002.

43. De Jong, G.; Gunn, H.; Walker, W. National and international freight transport models: An overview and ideas for future development. Transp. Rev. 2004, 24, 103-124. [CrossRef]

(C) 2019 by the authors. Licensee MDPI, Basel, Switzerland. This article is an open access article distributed under the terms and conditions of the Creative Commons Attribution (CC BY) license (http:/ / creativecommons.org/licenses/by/4.0/). 